Article

\title{
Artificial Neural Network (ANN) Approach to Modelling of Selected Nitrogen Forms Removal from Oily Wastewater in Anaerobic and Aerobic GSBR Process Phases ${ }^{\dagger}$
}

\author{
Piotr Ofman * (D) and Joanna Struk-Sokołowska \\ Department of Environmental Engineering Technology and Systems, Faculty of Civil and Environmental \\ Engineering, Bialystok University of Technology, 15-341 Bialystok, Poland \\ * Correspondence: p.ofman@pb.edu.pl; Tel.: +48-571-443-155 \\ † Presented at Innovations-Sustainability-Modernity-Openness Conference (ISMO'19), Bialystok, Poland, \\ 22-23 May 2019.
}

Received: 1 July 2019; Accepted: 28 July 2019; Published: 31 July 2019

\begin{abstract}
Paper presents artificial neural network models (ANN) approximating concentration of selected nitrogen forms in wastewater after sequence batch reactor operating with aerobic granular activated sludge (GSBR) in the anaerobic and aerobic phases. Aim of the study was to determine parameters conditioning effectiveness of selected nitrogen forms removal in GSBR reactor process phases. Models of artificial neural networks were developed separately for $\mathrm{N}-\mathrm{NH}_{4}, \mathrm{~N}-\mathrm{NO}_{3}$ and total nitrogen concentration in particular process phases of GSBR reactor. In total, 6 ANN models were presented in this paper. ANN models were made as multilayer perceptron (MLP), which were learned using the Broyden-Fletcher-Goldfarb-Shanno algorithm. Developed ANN models indicated variables the most influencing of particular nitrogen forms in aerobic and anaerobic phase of GSBR reactor. Concentration of estimated nitrogen form at the beginning of anaerobic or aerobic phase, depending on ANN model, in all ANN models influenced approximated value. Obtained determination coefficients varied from 0.996 to 0.999 and were depending on estimated nitrogen form and GSBR process phase. Hence, developed ANN models can be used in further studies on modeling of nitrogen forms in anaerobic and aerobic phase of GSBR reactors.
\end{abstract}

Keywords: GSBR; ANN model; nitrogen removal

\section{Introduction}

The most common form of activated sludge is flocked sludge. Most of papers refer to describeption of phenomena occurring during wastewater treatment with its usage. However, in recent years more interest has been directed towards aerobic granular activated sludge. According to definition presented by International Water Associacion, this form of activated sludge is referred as aggregates of microbiological nature, not coagulating under influence of shear forces and characterized by a lower sedimentation time compared to flocked sludge [1]. Many researchers presented both ability of this activated sludge form in removeing anthropogenic pollution from wastewater, as well as high tolerance to unfavorable conditions which may occur during wastewater treatment processes [2]. Wastewater contaminated with petroleum products, including oils and lubricants, are relatively onerous from the point of biological wastewater treatment. These substances limit gas exchange ratio of microorganisms involved in wastewater treatment processes [3]. It should be emphasized that despite numerous researches devoted to application possibilities of aerobic granular activated sludge, attempts for modeling of wastewater treatment process with its use are rarely undertaken [4] This results from fact 
that aerobic granular activated sludge technology is relatively new hence there is lack of sufficiently long research on objects operated in real conditions to create basis for software describing distribution kinetics of individual pollutants [5,6]. Modeling of new phenomena requires initial identification of factors influencing changes in variables set [7]. Static models, including artificial neural networks (ANN), allow to apply such approach. ANN algorithms are based on the simplest relationship between input and output variables. In case of wastewater treatment processes, ANN models most often take into account technological parameters of activated sludge and reactor or wastewater chemical properties. Due to possibility of arbitrary determination of input and output variables set, ANN models allow for precise reflrction of complex phenomena, including biological wastewater treatment processes. For this reason, artificial neural networks can closer define activated sludge technological parameters conditioning degradation processes of pollutants using aerobic granules [8].

Aim of the study was to develop artificial neural networks models to predict concentration of selected nitrogen forms in oily wastewater after anaerobic and aerobic phase of GSBR reactor, under fluctuating biological oxygen demand (BOD) loading rate conditions in wastewater inflowing into reactor and the determination of the most important activated sludge technological parameters for approximation of individual nitrogen forms concentration in anaerobic and aerobic phase.

\section{Materials and Methods}

Laboratory GSBR reactor was made of reinforced polyethylene (HDPE). Air was supplied by aerator with capacity of $550 \mathrm{dm}^{3} \cdot \mathrm{h}^{-1}$. During aerobic phase, concentration of dissolved oxygen in GSBR reactor chamber was maintained between 2.0 and $3.0 \mathrm{mg} \cdot \mathrm{dm}^{-3}$. Active volume of reactor was $15 \mathrm{dm}^{3}$. Reactor content was mixed using stirrer with rotational speed of 70 revolutions per minute (RPM). Volume exchange ratio in experiment was 0.33 for a single cycle. Duration of GSBR reactor unit phases, operation of air pump and mixer was coordinated with SIMENS programmable controller model LOGO! type 230RC.

Studies were carried out in 12-hour operation cycle, with $30 \mathrm{~min}$ filling phase duration, $90 \mathrm{~min}$ of mixing (anaerobic) phase, 540 min of mixing and aeration (aerobic) phase, 60 min of sedimentation phase, and $30 \mathrm{~min}$ of decantation phase [9]. Main studies were conducted for 58 days (116 full cycles of reactor operation), which were preceded by 30 days (60 full cycles) of activated sludge adaptation period. Concentration of activated sludge dry matter was maintained at level of $4.0 \mathrm{~kg} \cdot \mathrm{m}^{-3}$. Excess sludge was removed from reactor by bottom valve. Figure 1 presents structure of activated sludge used in study.



Figure 1. Structure of activated sludge used in studies.

Wastewater used in studies was prepared from peptone $\mathrm{K}\left(0.113-4.520 \mathrm{~g} \cdot \mathrm{dm}^{-3}\right)$,enriched dry broth $\left(0.076-3.040 \mathrm{~g} \cdot \mathrm{dm}^{-3}\right)$, which were primary sources of carbon, organic nitrogen and $\mathrm{N}-\mathrm{NO}_{3}, \mathrm{NH}_{4} \mathrm{Cl}$ $\left(0.010-0.400 \mathrm{~g} \cdot \mathrm{dm}^{-3}\right), \mathrm{NaCl}\left(6.59 \pm 0,01 \mathrm{~g} \cdot \mathrm{dm}^{-3}\right), \mathrm{CaCl}_{2} \cdot 6 \mathrm{H}_{2} \mathrm{O}\left(0.004-0.160 \mathrm{~g} \cdot \mathrm{dm}^{-3}\right), \mathrm{MgSO}_{4} \cdot 7 \mathrm{H}_{2} \mathrm{O}$ $\left(0.001-0.040 \mathrm{~g} \cdot \mathrm{dm}^{-3}\right), \mathrm{KH}_{2} \mathrm{PO}_{4}\left(0.008-0.320 \mathrm{~g} \cdot \mathrm{dm}^{-3}\right)$ and $\mathrm{K}_{2} \mathrm{HPO}_{4}\left(0.020-0.800 \mathrm{~g} \cdot \mathrm{dm}^{-3}\right)$, and oily 
substances $\left(0.032 \mu \mathrm{l} \cdot \mathrm{dm}^{-3}\right)$. Oily wastewater solution was prepared on the basis of naphtha (60\%), burned-out car oil (30\%), and petroleum oil (10\%). Quantities of reagents used for model wastewater preparation were selected in amounts allow to obtain active sludge BOD loading rate in range from 0.05 to $1.60 \mathrm{~kg} \mathrm{BOD} \cdot \mathrm{kg}^{-1} \cdot \mathrm{day}^{-1}$. Activated sludge BOD loading rate was increased when after 2 days (4 complete cycles) no changes in wastewater treatment efficiency were observed. Studies were carried out at room temperature $\left(20^{\circ} \mathrm{C} \pm 2{ }^{\circ} \mathrm{C}\right)$. Parameters of raw wastewater inflowing into GSBR reactor are presented in Table 1.

Table 1. Raw model wastewater parameters.

\begin{tabular}{cc}
\hline Parametr & Concentration Range \\
\hline BOD & $36.00-1200.00 \pm 340.51 \mathrm{mg} \cdot \mathrm{dm}^{-3}$ \\
COD & $57.00-1845.00 \pm 559.61 \mathrm{mg} \cdot \mathrm{dm}^{-3}$ \\
$\mathrm{~N}^{-N H} H_{4}$ & $1.03-34.51 \pm 10.52 \mathrm{mg} \cdot \mathrm{dm}^{-3}$ \\
$\mathrm{~N}-\mathrm{NO}_{3}$ & $4.66-153.24 \pm 46.88 \mathrm{mg} \cdot \mathrm{dm}^{-3}$ \\
Total N & $5.89-190.37 \pm 58.25 \mathrm{mg} \cdot \mathrm{dm}^{-3}$ \\
Oily substances & $0.032 \mu \mathrm{g} \cdot \mathrm{dm}^{-3}$ \\
\hline
\end{tabular}

Quantitative analysis of $\mathrm{N}-\mathrm{NH}_{4}, \mathrm{~N}-\mathrm{NO}_{3}$, Total $\mathrm{N}$ was performed by UV-VIS spectrophotometric method with Merck UV-VIS Pharo 300 spectrophotometer. Dedicated reagents from Merck were used for individual parameter determination. Samples preparation for analysis was carried out in accordance with methodology appended by manufacturer. Considered technological parameters of activated sludge were calculated based on following equations:

Sludge volume index:

$$
\mathrm{SVI}=\frac{\mathrm{V}_{\mathrm{OS}_{30}}}{\mathrm{G}}
$$

Hydraulic retention time:

$$
\mathrm{HRT}=\frac{\mathrm{V}_{\mathrm{RP}} \times \mathrm{G}}{\Delta \mathrm{G}}
$$

Sludge retention time:

$$
\mathrm{SRT}=\mathrm{HRT} \times \frac{\mathrm{t}_{\mathrm{R}}}{\mathrm{t}_{\mathrm{C}}}
$$

Activated sludge BOD loading rate:

$$
\mathrm{A}^{\prime}=\frac{\mathrm{Q}_{\mathrm{d}} \times \mathrm{S}_{\mathrm{BOD}}}{\mathrm{V}_{\mathrm{RP}} \cdot \mathrm{G}} \times \frac{\mathrm{t}_{\mathrm{R}}}{\mathrm{t}_{\mathrm{C}}}
$$

In presented equations $\mathrm{V}_{\mathrm{os} 30}$ constituted for sludge volume after 30 min of sedimentation in cylinder of $1000 \mathrm{~cm}^{3}$ capacity, G was activated sludge dry mass, $V_{R P}$ was maximum GSBR reactor capacity, $\Delta G$ constituted for activated sludge growth rate, $t_{R}$ and $t_{C}$ stated for duration of aeration phase and duration of single GSBR operation cycle respectively, $Q_{d}$ stated for daily amount of raw wastewater inflowing to GSBR reactor and $\mathrm{S}_{\mathrm{BOD}}$ stated for BOD concentration in raw wastewater. In Table 2 are presented technological parameters of activated sludge that were maintained or observed during experiment.

Table 2. Activated sludge technological parameters.

\begin{tabular}{ccc}
\hline Activated Sludge Technological Parameter & Unit & Value Range \\
\hline Activated sludge dry mass & $\mathrm{kg} \cdot \mathrm{m}^{-3}$ & $4.0 \pm 0.1$ \\
Sludge volume index & $\mathrm{cm}^{3} \cdot \mathrm{g}^{-1}$ & $59-70 \pm 3$ \\
Hydraulic retention time & $\mathrm{d}$ & $31-60 \pm 11$ \\
Sludge retention time & $\mathrm{d}$ & $21-42 \pm 7$ \\
\hline
\end{tabular}


Multilayer perceptron (MLP) artificial neural networks were used for concentrations prediction of individual nitrogen forms. Input variables in each network constituted concentration of approximated nitrogen form, BOD load, and activated sludge basic technological parameters, including sludge volume index, hydraulic retention time and sludge retention time.

Developed ANN models allowed to indicate variables greatest on modeling process of changes occurring in removal of particular nitrogen forms in anaerobic and aerobic phases of reactor. For this reason, basic technological values describing behavior ofsludge volume index, hydraulic retention time, and sludge retention time were adopted as input variables models. Additionally, selection of these variables was dictated by addition of oily substances to wastewater, which may inhibit biological wastewater treatment processes. Moreover, these variables were strongly correlated (Table 3) with concentrations of individual nitrogen forms in both anaerobic and aerobic phases.

Table 3. Correlation coefficients between technological parameters of activated sludge and concentration of selected nitrogen forms in anaerobic and aerobic phase.

\begin{tabular}{lccccccc}
\hline \multicolumn{3}{c}{ Correlations in Anaerobic Phase } & \multicolumn{3}{c}{ Correlations in Aerobic Phase } \\
\hline Variable & SVI & HRT & SRT & Variable & SVI & HRT & SRT \\
\hline $\mathbf{N}^{-N}{ }_{3}$ & -0.79 & -0.82 & -0.83 & N-NO & -0.78 & -0.78 & -0.79 \\
$\mathbf{N}_{\mathbf{N H}}$ & -0.79 & -0.83 & -0.84 & $\mathbf{N}-\mathbf{N H}_{4}$ & -0.78 & -0.86 & -0.88 \\
Total N & -0.79 & -0.84 & -0.85 & Total N & -0.78 & -0.81 & -0.82 \\
\hline
\end{tabular}

Consideration of BOD loading rate and concentration of selected nitrogen form in input layer allowed to increase models accuracy by adding variables describing chemical composition of treated wastewater. Influence of individual variable in ANN model on approximated variable was evaluated by weight analysis, which was performed automatically at development stage. Weight $(w)$ of given input variable can be interpreted as accuracy coefficient describing relation between output and given input variable. Best algorithm was selected from sampling among 500 networks. Broyden-Fletcher-Goldfarb-Shanno (BFGS) was used. BFGS algorithm was used due to fact that in previous work on modeling wastewater treatment processes using ANN models [10,11] it allowed to obtain the best results. Maximum number of epochs was 200 in all networks training. Purpose of such approach was to limit ANN overfitting risk. Error function in all algorithms was sum of squares (SOS). Estimation error values were determined in accordance with following equation:

$$
\mathrm{SOS}=\sum_{\mathrm{i}=1}^{\mathrm{n}}\left(\mathrm{x}_{\mathrm{i}}-\overline{\mathrm{x}_{\mathrm{i}}}\right)^{2}
$$

In all ANN models in hidden and initial layer linear function, hyperbolic tangent, logistic, exponential and sine as activation functions of layer were considered. ANN models were developed using Statistica version 13.1 software operating on Windows 10 platform, 696 measurement results were used. Table 4 presents network topology, training algorithm, error function and activation function of neurons in hidden and input layer in developed ANN models.

Table 4. Developed ANN model's basic parameters.

\begin{tabular}{|c|c|c|c|c|c|}
\hline $\begin{array}{c}\text { Approximated N Form in } \\
\text { Selected GSBR Process } \\
\text { Phase }\end{array}$ & ANN Type & $\begin{array}{l}\text { Machine Learning } \\
\text { Algorithm and } \\
\text { Epochs }\end{array}$ & $\begin{array}{l}\text { Error } \\
\text { Function }\end{array}$ & $\begin{array}{l}\text { Hidden Layer } \\
\text { Activation } \\
\text { Function }\end{array}$ & $\begin{array}{l}\text { Output Layer } \\
\text { Activation } \\
\text { Function }\end{array}$ \\
\hline $\mathrm{N}-\mathrm{NO}_{3}$ in anaerobic phase & MLP 5-6-1 & BFGS 118 & SOS & Logistic & Logistic \\
\hline $\mathrm{N}-\mathrm{NH}_{4}$ in anaerobic phase & MLP 5-7-1 & BFGS 174 & SOS & Logistic & Tanh \\
\hline Total $\mathrm{N}$ in anaerobic phase & MLP 5-9-1 & BFGS 124 & SOS & Logistic & Tanh \\
\hline $\mathrm{N}-\mathrm{NO}_{3}$ in aerobic phase & MLP 5-9-1 & BFGS 56 & SOS & Logistic & Exponential \\
\hline $\mathrm{N}-\mathrm{NH}_{4}$ in aerobic phase & MLP 5-4-1 & BFGS 122 & SOS & Logistic & Tanh \\
\hline Total $\mathrm{N}$ in aerobic phase & MLP 5-3-1 & BFGS 73 & sOS & Logistic & Linear \\
\hline
\end{tabular}




\section{Results}

Developed artificial neural networke models allowed for accurate representation of changes trend of individual forms of nitrogen both in anaerobic and aerobic phases of GSBR reactor (Table 5). ANN model describing $\mathrm{N}_{-} \mathrm{NO}_{3}$ changes in anaerobic phase revealed over $99 \%$ of the changes $(r$ $=0.999$ ). Model estimation error was $1.373 \mathrm{mg} \cdot \mathrm{dm}^{-3}$. The most significant variable influencing calculation course of developed algorithm was BOD loading rate entering GSBR reactor $(w=82.37)$. $\mathrm{N}-\mathrm{NO}_{3}$ concentration at the beginning of anaerobic phase $(w=71.84)$ affected calculations to lesser extent, while variables to the least extent influencing approximated $\mathrm{N}-\mathrm{NO}_{3}$ values were technological

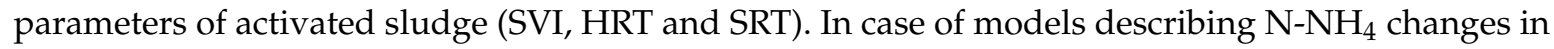
anaerobic phase, an adjustment between observed and approximated values of over 99\% was obtained $(r=0.999)$. Model approximation error was $0.061 \mathrm{mg} \cdot \mathrm{dm}^{-3}$, while variable that had the greatest influence on algorithm calculation course was $\mathrm{N}-\mathrm{NH}_{4}$ concentration the beginning of anaerobic phase $(w=1215.16)$. Remaining variables showed a significantly smaller influence on approximation result. Model describing changes in total nitrogen after anaerobic phase reveled over $99 \%$ of changes $(r$ $=0.999$ ). Model estimation error was $2.757 \mathrm{mg} \cdot \mathrm{dm}^{-3}$. However, variables that had a major influence on model calculation were total nitrogen concentration in wastewater at the beginning of anaerobic phase $(w=87.47)$ and activated sludge BOD loading rate $(w=84.34)$. Other variables had a lesser effect on approximated total nitrogen concentration.

Table 5. Sensitivity analysis and ANNs matching to observed values.

\begin{tabular}{|c|c|c|c|c|c|c|c|c|}
\hline \multirow{2}{*}{$\begin{array}{c}\text { ANN } \\
\text { Topology }\end{array}$} & \multirow{2}{*}{$\begin{array}{l}\text { Estimated N } \\
\text { Form }\end{array}$} & \multicolumn{5}{|c|}{ Variables Rank $(w)$} & \multirow{2}{*}{$\begin{array}{c}\text { ANN Prediction } \\
\text { Quality }(r)\end{array}$} & \multirow{2}{*}{$\begin{array}{l}\text { ANN } \\
\text { Error }\end{array}$} \\
\hline & & BOD Load & N Form & SRT & SVI & HRT & & \\
\hline $\begin{array}{l}\text { MLP } \\
5-6-1\end{array}$ & $\begin{array}{c}\mathrm{N}-\mathrm{NO}_{3} \text { in } \\
\text { anaerobic phase }\end{array}$ & 82.37 & 71.84 & 3.33 & 1.68 & 1.20 & 0.999 & 1.373 \\
\hline $\begin{array}{l}\text { MLP } \\
5-7-1\end{array}$ & $\begin{array}{c}\mathrm{N}-\mathrm{NH}_{4} \text { in } \\
\text { anaerobic phase }\end{array}$ & 22.77 & 1215.16 & 5.47 & 3.85 & 7.70 & 0.999 & 0.061 \\
\hline $\begin{array}{l}\text { MLP } \\
5-9-1\end{array}$ & $\begin{array}{c}\text { Total } \mathrm{N} \text { in } \\
\text { anaerobic phase }\end{array}$ & 84.34 & 87.47 & 3.06 & 3.69 & 1.06 & 0.999 & 2.757 \\
\hline $\begin{array}{l}\text { MLP } \\
5-9-1\end{array}$ & $\begin{array}{c}\mathrm{N}-\mathrm{NO}_{3} \text { in } \\
\text { aerobic phase }\end{array}$ & 46.80 & 46.42 & 6.97 & 1.36 & 2.97 & 0.998 & 1.115 \\
\hline $\begin{array}{l}\text { MLP } \\
5-4-1\end{array}$ & $\begin{array}{l}\mathrm{N}_{-} \mathrm{NH}_{4} \text { in } \\
\text { aerobic phase }\end{array}$ & 59.43 & 69.98 & 7.23 & 3.60 & 4.49 & 0.998 & 0.139 \\
\hline $\begin{array}{l}\text { MLP } \\
5-3-1\end{array}$ & $\begin{array}{l}\text { Total } \mathrm{N} \text { in } \\
\text { aerobic phase }\end{array}$ & 30.37 & 30.75 & 2.58 & 2.12 & 2.67 & 0.996 & 3.950 \\
\hline
\end{tabular}

ANN model describing $\mathrm{N}-\mathrm{NO}_{3}$ changes in aerobic phase of GSBR reactor revealed more than $99 \%$ of changes $(r=0.998)$. Model estimation error was $1.115 \mathrm{mg} \cdot \mathrm{dm}^{-3}$. However, variables that had the greatest influence on calculations accuracy were the BOD loading rate $(w=46.80)$ and $\mathrm{N}-\mathrm{NO}_{3}$ concentration at the beginning of aerobic phase $(w=46.42)$. Variables describing activated sludge technological parameters influenced calculation process to a much smaller extent $(w=6.97 ; 2.97$ and 1.36). In case of model describing $\mathrm{N}-\mathrm{NH}_{4}$ changes in aerobic phase, over $99 \%$ adjustment to actual values was observed $(r=0.998)$. Model estimation error was $0.139 \mathrm{mg} \cdot \mathrm{dm}^{-3}$, the most significant variables that influencing approximated value were $\mathrm{N}-\mathrm{NH}_{4}$ concentration at the beginning of aerobic phase $(w=69.98)$ and activated sludge BOD loading rate $(w=59.43)$. Remaining variables were characterized by a smaller influence on algorithm's calculation course. SRT, HRT and SVI weights were equal to $7.23,4.49$, and 3.60 respectively. Model describing changes of total nitrogen during aeration phase reveled over $99 \%$ of changes $(r=0.996)$. Model estimation error was $3.950 \mathrm{mg}^{\circ} \mathrm{dm}^{-3}$. Model calculation course was influenced mainly by total nitrogen concentration at the beginning of aerobic phase $(w=30.75)$ and BOD loading rate $(w=30.37)$. Other variables (SVI, SRT and HRT) had a significantly smaller effect on approximation accuracy of developed ANN model. Figures 2-7 show a comparison of actual values and values approximated by particular ANN models. All models 
accurately reflected changes of individual nitrogen forms both in anaerobic and aerobic phase. Apart from general trend, developed models accurately described changes at extreme points.



Figure 2. Approximated and observed concentrations of $\mathrm{N}-\mathrm{NO}_{3}$ after GSBR anaerobic phase.

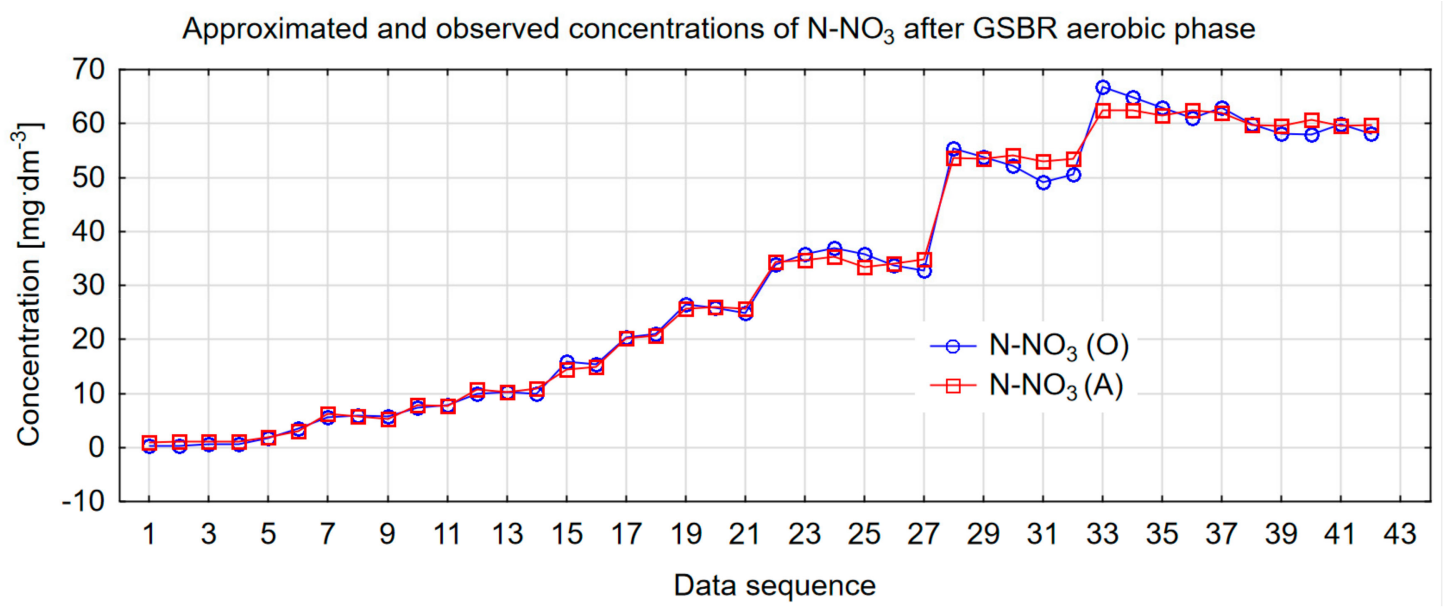

Figure 3. Approximated and observed concentrations of $\mathrm{N}-\mathrm{NO}_{3}$ after GSBR aerobic phase.

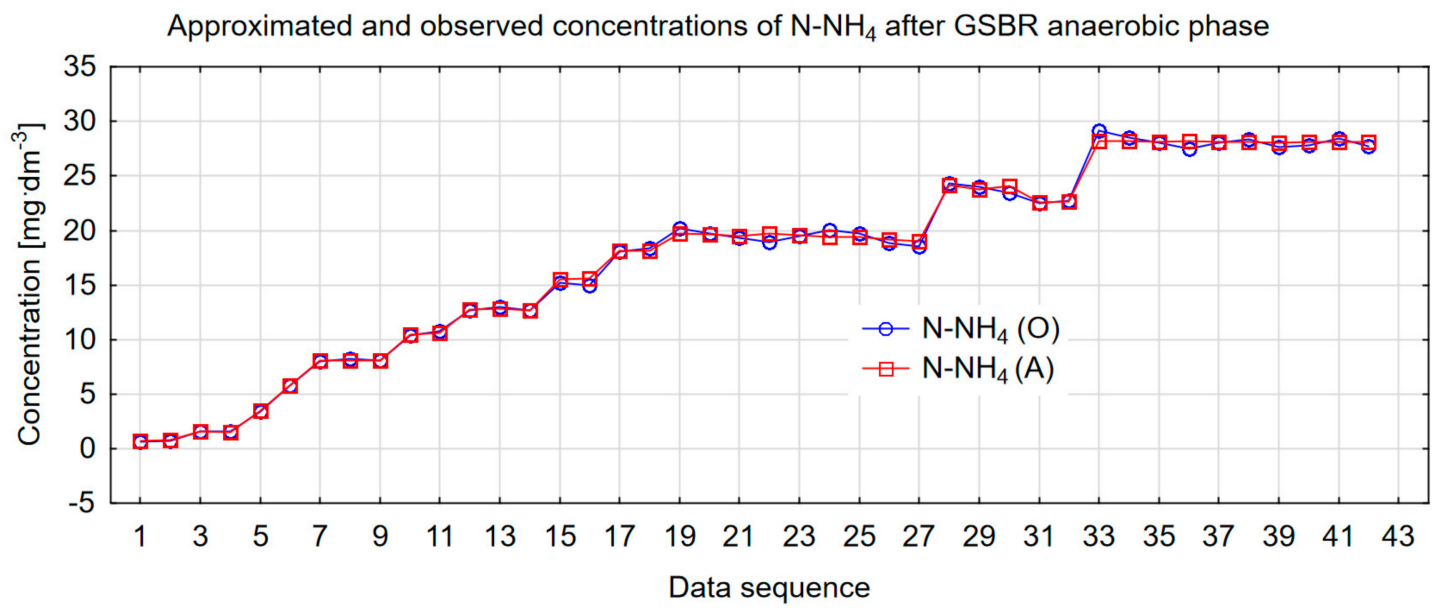

Figure 4. Approximated and observed concentrations of $\mathrm{N}^{-\mathrm{NH}_{4}}$ after GSBR anaerobic phase. 


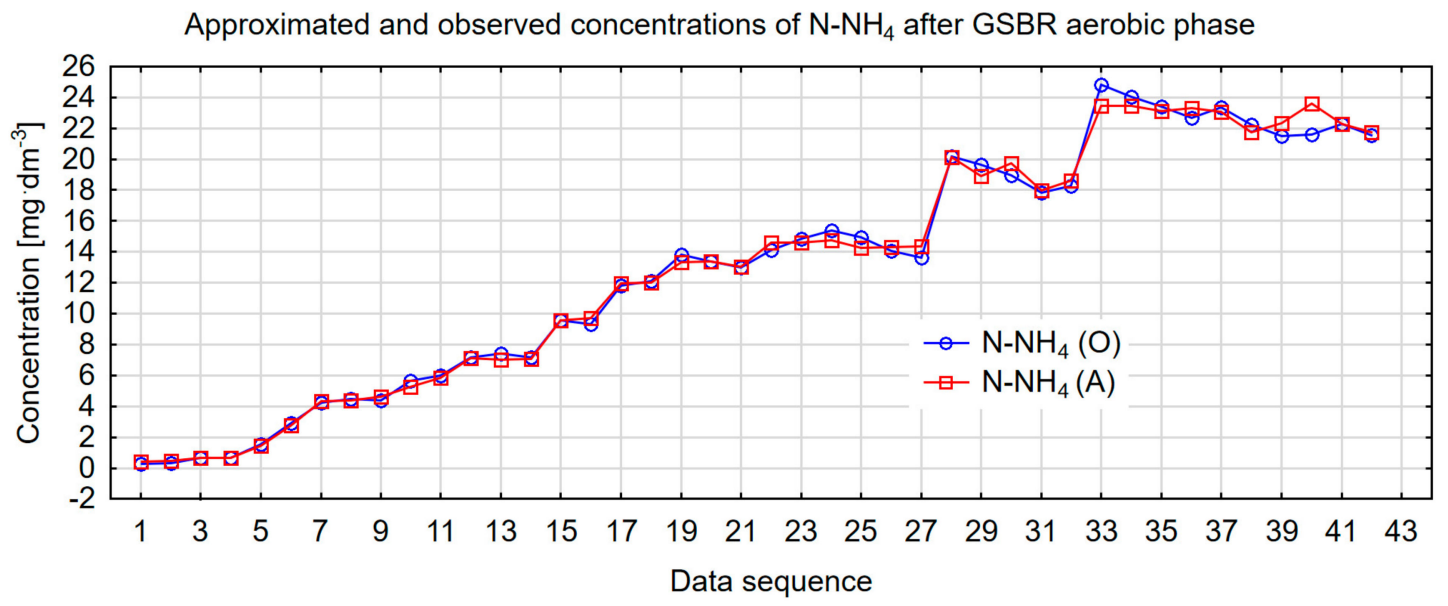

Figure 5. Approximated and observed concentrations of $\mathrm{N}-\mathrm{NH}_{4}$ after GSBR aerobic phase.

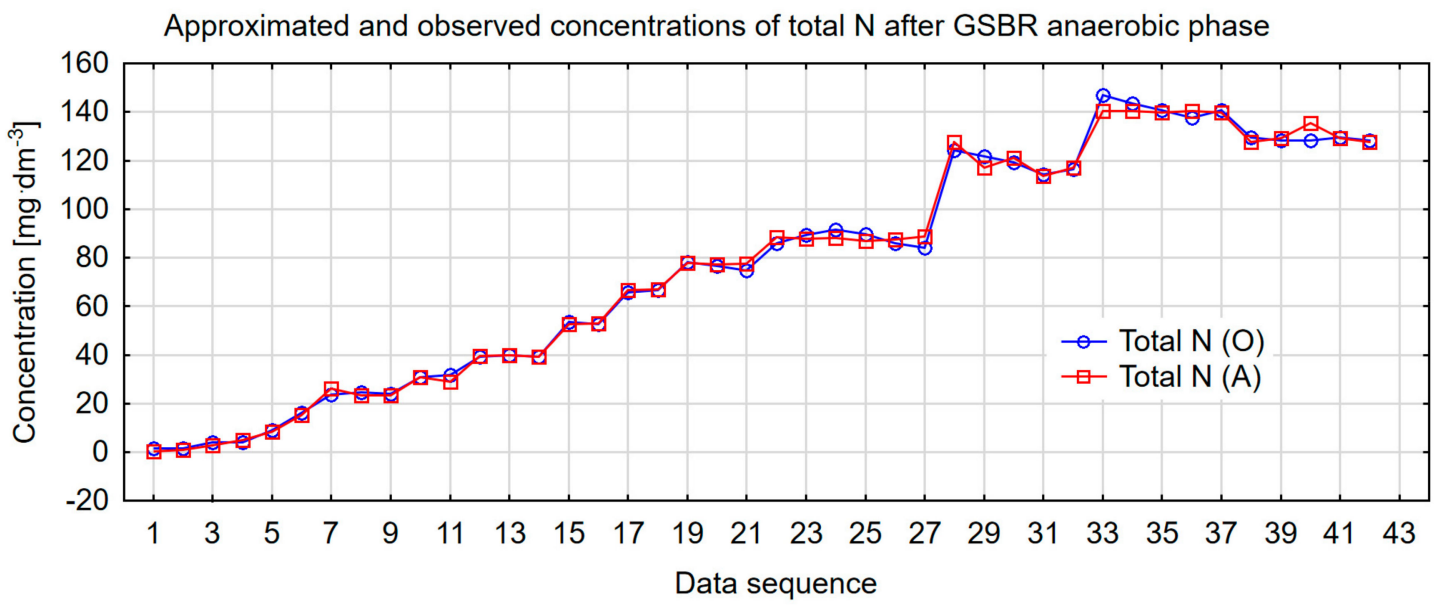

Figure 6. Approximated and observed concentrations of total N after GSBR anaerobic phase.

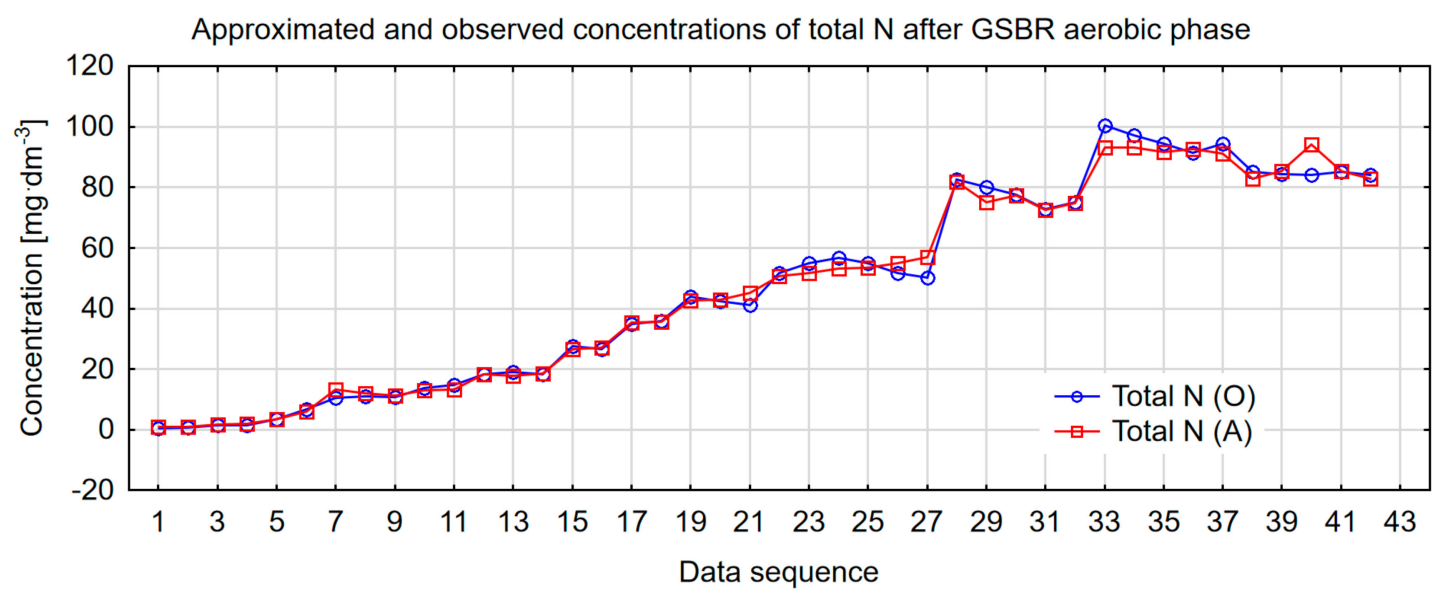

Figure 7. Approximated and observed concentrations of total $\mathrm{N}$ after GSBR aerobic phase.

Characteristic feature of static models created on basis of database is ability to freely select variables that serve as predictors of approximated variable [12,13]. Arbitrary variables selection in this type of models allows to omit kinetic variables, which may be difficult to determine, especially for new media such as aerobic granulated activated sludge [14,15]. In case of wastewater treatment processes, both quantities describing chemical properties of wastewater inflowing to reactor and indicators approximating activity of microorganisms present in activated sludge, expressed as technological 
parameters of activated sludge [16], may be important. Ability of arbitrary selection of variables in creation process of ANN model also involves cognitive aspect of given phenomenon [17]. Based on rank analysis of individual input variables, significance classification in terms of their influence on approximated value can be made [18]. Ranking allow better understanding of changes observed during given process [19]. Inclusion of variables describing chemical composition of wastewater and technological parameters of activated sludge makes it possible to indicate quantities that may have catalytic or inhibitory effect on treatment process, and also allows to indicate parameters that are less important at given stage of wastewater treatment [20].

Developed ANN models allowed to indicate variables mainly influencing changes in particular forms of nitrogen in aerobic and anaerobic phase of GSBR reactor. In all developed ANN models, concentration of estimated nitrogen form at the beginning of the anaerobic or aerobic phase, depending on ANN model, significantly influenced approximated value. Additionally, in most models key parameter was loading of activated sludge with BOD. Both of these variables are directly related to quality of wastewater inflowing to reactor during experiment. In all developed ANNs, technological parameters of activated sludge had less influence on approximation. Considered in model parameters of activated sludge are indirectly related to each other and contain some values describ quality of wastewater inflowing to reactor. Therefore, use of those variables indirectly allowed to include both chemical parameters of raw wastewater (BOD) in further stages of wastewater treatment. However, a smaller impact of these variables (SRT, HRT and SVI) could be caused by fact that effects of wastewater treatment in particular stages (anaerobic and aerobic phases) did not differ significantly in percentage terms, and changes were observed only in higher concentrations of particular raw wastewater parameters, dictated by increased BOD loading inflowing to reactor. Nevertheless, developed artificial neural network models indicate that changes in concentration of nitrogen forms after anaerobic and aerobic phase of GSBR reactor are mostly influenced by BOD loading rate inflowing to reactor and concentration of particular nitrogen form at the beginning of process phase. Technological parameters of activated sludge are less important, which results from high tolerance of aerobic granulated activated sludge to changes in BOD loading rate inflowing to reactor [2].

\section{Discussion}

Similar adjustments between observed and approximated values of $\mathrm{N}-\mathrm{NH}_{4}$ was obtained by Zaghloul et al. [21] in a model describing biomass behavior and wastewater treatment process in a model SBR reactor with granulated aerobic sludge fed with model wastewater. In models input layer authors have included raw wastewater parameters ( $\mathrm{N}-\mathrm{NH}_{4}$ and $\mathrm{PO}_{4}{ }^{3-}$ concentrations) and $\mathrm{pH}$ value, as well as technological parameters of reactor and activated sludge, including organic load (COD), volumetric exchange coefficient, sedimentation time and amount of air supplied to reactor. Model developed by Zaghloul et al. [21] was more complex compared to models presented in this work. With more variables taken into account model, prediction accuracy increases. It should be noted, however, that for larger number of variables it is difficult to identify those that have the greatest impact on changes occurring during wastewater treatment. Therefore, simpler models are essential for identifying key variables responsible for selected pollutant removal. Nevertheless, degree to which compared models reflected changes in $\mathrm{N}_{-} \mathrm{NH}_{4}$ concentration was similar and amounted to over 99\% $(r=0.9987)$. Hong et al. [22] developed model of artificial neural network describing changes in $\mathrm{NH}_{4}{ }^{+}, \mathrm{NO}_{3}{ }^{-}$ and $\mathrm{PO}_{4}{ }^{3-}$ in anaerobic and aerobic phases of SBR reactor fed with model wastewater and operating under laboratory conditions. Input variables in model were $\mathrm{pH}$ value, redox potential, dissolved oxygen concentration and concentrations of nitrogen and phosphorus, whereas 390 measurement results were used model creation. Mean approximation error in anaerobic phase with which developed ANN model estimated individual values was 1.687, whereas in aerobic phase it was 0.809 . These values were comparable with error values obtained in presented models. Hong et al. [22] pointed out that developing single model describing entire wastewater treatment process in SBR reactor did not provide satisfactory results. Authors emphasize that this may have been caused by changes in oxygen 
conditions between the anaerobic and aeration phase. Bagheri et al. [23] developed ANN model to describing performance of model sequencing batch reactor (SBR) treating domestic wastewater. In input layer, authors took into consideration quality parameters of wastewater inflowing to reactor, such as $\mathrm{COD}, \mathrm{NH}_{4}$, total phosphorus, and total suspended solids as well as technological parameters describing duration of particular process phases, SVI, HRT and mixed liquor volatile suspended solids (MLVSS), whereas in output layer only chemical parameters of treated wastewater (COD, $\mathrm{NH}_{4}$, total phosphorus and total suspended solids) were included. Database used for model development consisted 700 measurement results. The Bagheri et al. [23] model, error of $\mathrm{NH}_{4}$ estimation in treated wastewater was $0.12 \mathrm{mg} \cdot \mathrm{dm}^{-3}$, and $r$ coefficient was 0.99 , these values were similar to ANN parameters presented in this paper. Compared to Bagheri et al. [23] model, duration of individual process phases of GSBR reactor was not included in input layer, mainly due to fact that their durations were constant during experiment. Nevertheless, both duration of anaerobic phase and aeration is key factor in determining extent of denitrification and nitrification [24].

\section{Conclusions}

Developed artificial neural network models reflected over $99 \%$ changes in concentration of individual nitrogen forms both in anaerobic and aerobic phases of GSBR reactor. Individual ANN models accurately reflected nature of $\mathrm{N}-\mathrm{NH}_{4}, \mathrm{~N}-\mathrm{NO}_{3}$, and total nitrogen changes under fluctuating activated sludge BOD loading rate in range from 0.05 to $1.60 \mathrm{~kg} \mathrm{BOD} \cdot \mathrm{kg}^{-1} \cdot \mathrm{m}^{-3}$.

The most significant influence on approximation of $\mathrm{N}^{-\mathrm{NH}_{4}}$ and $\mathrm{N}-\mathrm{NO}_{3}$, both in anaerobic and aerobic phases, was caused by concentration of these nitrogen forms at the beginning of modeled phase. In case of total nitrogen, however, BOD loading rate had a greater influence on calculation course of approximation algorithm.

Despite high correlation coefficients between concentrations of individual nitrogen forms in aerobic and anaerobic phase and considered activated sludge technological parameters, no significant influence of technological parameters on ANN calculation course was observed. In particular model, technological parameters of activated sludge (SVI, HRT, and SRT) had a similar effect on calculations quality, which could be caused by fact that one of aerobic granular activated sludge properties is resistance to fluctuations in organic compound load inflowing to reactor.

Further studies on modeling of oily wastewater treatment processes in GSBR reactors should take into account a wider range of activated sludge and reactor technological parameters. This will allow for better description of changes occurring during wastewater treatment in aerobic and anaerobic phases. Additionally, indication of other key technological parameters will contribute to optimization of nitrogen removal in GSBR reactors. As a result, in wider perspective, ANN models could be used for control of wastewater treatment plants operating in technology of aerobic granular activated sludge.

Author Contributions: P.O., J.S.-S.—conceptualization, methodology, investigation, formal analysis, and article writing and editing, P.O.- data curation, article editing, P.O.—article writing and editing.

Funding: The research was carried out as part of research project no. WZ/WBiIŚ/8/2019 at Białystok University of Technology and financed from subsidy provided by the Minister of Science and Higher Education.

Acknowledgments: Authors would like to thank Head of Department of Environmental Engineering Technology and Systems for supporting research and providing materials used in experiment.

Conflicts of Interest: The authors declare no conflict of interest.

\section{References}

1. Corsino, S.F.; Capodici, M.; Morici, C.; Torregrossa, M. Simltaneous nitrition-denitrition for the treatment of high-strength nitrogen in hypersaline wastewater by aerobic granular sludge. Water Res. 2016, 88, 329-336. [CrossRef] [PubMed]

2. Adav, S.S.; Lee, D.J.; Show, K.Y.; Tay, J.H. Aerobic granular sludge: Recent advances. Biotechnol. Adv. 2008, 26, 411-423. [CrossRef] [PubMed] 
3. Jamaly, S.; Giwa, A.; Hasan, S.W. Recent improvements in oily wastewater treatment: Progress, challenges, and future opportunities. J. Environ. Sci. 2015, 37, 15-30. [CrossRef] [PubMed]

4. Ni, B.J.; Yu, H.Q. Mathematical modelling of aerobic granular sludge: A review. Biotechnol. Adv. 2010, 28, 895-909. [CrossRef] [PubMed]

5. Baeten, J.E.; van Loosdrecht, M.C.M.; Volcke, E.I.P. Modelling aerobic granular sludge reactors through apparent half-saturation coefficients. Water Res. 2018, 146, 134-145. [CrossRef] [PubMed]

6. Harrou, F.; Dairi, A.; Sun, Y.; Senouci, M. Statistical monitoring of a wastewater treatment plant: A case study. J. Environ. Manag. 2018, 223, 807-814. [CrossRef] [PubMed]

7. Dabrowski, W.; Karolniczak, B.; Malinowski, P.; Boruszko, D. Modeling of pollutants removal in subsurface vertical flow and horizontal flow constructed wetlands. Water 2019, 11, 180. [CrossRef]

8. Baeten, J.E.; Batstone, D.J.; Schraa, O.; van Loosdrecht, M.C.M.; Volcke, E.I.P. Modelling anaerobic, aerobic and partial nitritation-anammox granular sludge reactors-A review. Water Res. 2019, 149, 322-341. [CrossRef]

9. Ofman, P.; Skoczko, I. PAH removal effectiveness comparison from hydraulic fracturing model wastewater in SBR reactors with granular and flocked activated sludge. Desalin. Water Treat. 2018, 134, 41-51. [CrossRef]

10. Skoczko, I.; Struk-Sokołowska, J.; Ofman, P. Modeling changes in the parameters of treated sewage using artificial neural networks. Annu. Set Env. Prot. 2017, 19, 633-650.

11. Skoczko, I.; Ofman, P.; Szatyłowicz, E. Using artificial neural networks for modeling wastewater treatment in small wastewater treatment plans. Annu. Set Environ. Prot. 2016, 18, 493-506.

12. Nasr, M.S.; Moustafa, M.A.E.; Seif, H.A.E.; El Kobrosy, G. Application of artificial neural network (ANN) for prediction of EL-AGAMY wastewater treatment plant performance-EGYPT. Alex. Eng. J. 2012, 51, 37-43. [CrossRef]

13. Giwa, A.; Daer, S.; Ahmed, I.; Marpu, P.R.; Hasan, S.W. Experimental investigation and artificial neural networks ANNs modeling of electrically-enhanced membrane bioreactor for wastewater treatment. J. Water Process. Eng. 2016, 11, 88-97. [CrossRef]

14. Vázquez-Padín, J.R.; Mosquera-Corral, A.; Campos, J.L.; Méndez, R.; Carrera, J.; Pérez, J. Modelling aerobic granular SBR at variable $\mathrm{COD} / \mathrm{N}$ ratios including accurate description of total solids concentration. Biochem. Eng. J. 2010, 49, 173-184. [CrossRef]

15. Zhou, M.; Gong, J.; Yang, C.; Pu, W. Simulation of the performance of aerobic granular sludge SBR using modified ASM3 model. Bioresour. Technol. 2013, 127, 473-481. [CrossRef] [PubMed]

16. Shmitt, F.; Banu, R.; Yeom, I.T.; Do, K.U. Development of artificial neural networks to predict membrane fouling in an anoxic-aerobic membrane bioreactor treating domestic wastewater. Biochem. Eng. J. 2018, 133, 47-58. [CrossRef]

17. Hayder, G.; Ramil, M.Z.; Malek, M.A.; Khamis, A.; Hilmin, N.M. Prediction model development for petroleum refinery wastewater treatment. J. Water Process Eng. 2014, 4, 1-5. [CrossRef]

18. Corominas, L.; Garrido-Baserba, M.; Villez, K.; Olsson, G.; Cortés, U.; Poch, M. Transforming data into knowledge for improved wastewater treatment operation: A critical review of techniques. Environ. Model. Softw. 2018, 106, 89-103. [CrossRef]

19. Guo, Y.M.; Liu, Y.G.; Zeng, G.M.; Hu, X.J.; Xu, W.H.; Liu, Y.Q.; Liu, S.M.; Sun, H.S.; Ye, J.; Huang, H.J. An integrated treatment of domestic wastewater using sequencing batch biofilm reactor combined with vertical flow constructed wetland and its artificial neural network simulation study. Ecol. Eng. 2014, 64, 18-26. [CrossRef]

20. Asadi, A.; Verma, A.; Yang, K.; Mejabi, B. Wastewater treatment aeration process optimization: A data mining approach. J. Environ. Manag. 2017, 203, 630-639. [CrossRef]

21. Zaghloul, M.S.; Hamaza, R.A.; Iorhemen, O.T.; Tay, J.H. Performance prediction of an aerobic granular SBR using modular multilayer artificial neural networks. Sci. Total. Environ. 2018, 645, 449-459. [CrossRef] [PubMed]

22. Hong, S.H.; Lee, W.M.; Lee, D.S.; Park, J.M. Monitoring of sequencing batch reactor for nitrogen and phosphorus removal using artificial neural networks. Bioche. Eng. J. 2007, 35, 365-370. [CrossRef] 
23. Bagheri, M.; Mirbagheri, S.A.; Ehteshami, M.; Bagheri, Z. Modeling of a sequencing batch reactor treating municipal wastewater using multi-layer perceptron and radial basis function artificial neural networks. Process Saf. Environ. Prot. 2015, 93, 111-123. [CrossRef]

24. Qian, W.; Ma, B.; Li, X.; Zhang, Q.; Peng, Y. Long-term effect of $\mathrm{pH}$ on denitrification: High $\mathrm{pH}$ benefits achieving partial-denitrification. Bioresour. Technol. 2019, 278, 444-449. [CrossRef] [PubMed]

(C) 2019 by the authors. Licensee MDPI, Basel, Switzerland. This article is an open access article distributed under the terms and conditions of the Creative Commons Attribution (CC BY) license (http://creativecommons.org/licenses/by/4.0/). 